\title{
EFFECT OF SIMULATED GASTRIC ACID ON SURFACE ROUGHNESS OF DIFFERENT MONOLITHIC CERAMICS
}

\author{
Mohamed F Aldamaty **, Khaled M Haggag **, Hesham I Othman **
}

\begin{abstract}
Objectives: The purpose of this study was to evaluate the effect of simulated gastric acid on surface roughness of monolithic ceramics. Materials and methods: A total of forty ceramic disk-shaped specimens were obtained from four ceramic materials (10 each). Each disk was sawed with a final thickness of $1.0 \mathrm{~mm}$ using Isomet saw from ceramic blocks of each material (Ceramil Zolid fx white $\{$ Z $\}$, IPS e.max CAD $\{$ E $\}$ HT A3, Vita Suprinity $\{$ S $\}$ HT A3, and Cerasmart $\{C\}$ HT A3). Ceramil Zolid fx white disks were colored with A3 coloring liquid and sintered, while e.max CAD and Vita Suprinity were crystallized according to manufacturer's instructions. Surface roughness of ceramic disks was measured with a stylus profilometer before and after immersion in simulated gastric acid $(\mathrm{HCl})$ for $96 \mathrm{~h}$ at $37{ }^{\circ} \mathrm{C}$ in an incubator. The collected data were statistically analyzed using ANOVA followed by Tukey's post-hoc test and the significance level was set at $\mathrm{P} \leq 0.05$. Results: There was no statistically significant difference $(\mathrm{P}>$ $0.05)$ for $\mathrm{Z}$ and $\mathrm{E}$ groups after acid immersion, while for $\mathrm{S}$ and $\mathrm{C}$ groups, there was a statistically significant difference $(\mathrm{P}<0.05)$ after acid immersion. Conclusion: Surface roughness increased significantly for Vita Suprinity and Cerasmart after gastric acid immersion, while it decreased for Zolid fx and IPS e.max CAD but not significantly.
\end{abstract}

KEYWORDS: Gastric Acid, GERD, Monolithic Ceramics, Surface Roughness.

\section{INTRODUCTION}

Over the past 20 years, dental erosion has become a topic of interest in general dentistry regarding its causes, diagnosis, as well as management. It is considered one of the main factors of tooth wear in which loss of tooth structure occurs by acids due to non-bacterial causes ${ }^{(1)}$.

The continuous acid attack renders the tooth surface to be more susceptible to abrasive wear. These erosive acids can be of intrinsic origin, as in stomach acid, or extrinsic as that of acidic beverages and citrus fruits ${ }^{(2)}$. To emphasize, gastric acid has a lower PH and a more erosive ability than dietary acids, hence the amount of destruction is unfortunately more severe ${ }^{(3)}$.

Gastroesophageal reflux disease (GERD) is a common medical condition causing involuntary gastric acid movement into the oral cavity. It is a relatively common condition worldwide, with prevalence rates in adults ranging from $21 \%$ to $56 \%$ in different countries. $15 \%$ of individuals experience heartburn once a week, $7 \%$ to $10 \%$ experience heartburn once daily, $25 \%$ to $40 \%$ of Americans experience symptomatic GERD at some point, and $45 \%$ to $85 \%$ of women experience GERD or heartburn during pregnancy ${ }^{(4,5)}$.

* Assistant Lecturer, Crown and Bridge Department, Faculty of Dental Medicine, Al-Azhar University, (BoysCairo), Egypt.

** Professor, Crown and Bridge Department, Faculty of Dental Medicine, Al-Azhar University, (Boys-Cairo), Egypt.

-Corresponding author: dr.damaty86@gmail.com

DOI: 10.21608 /ajdsm.2020.34007.1070 
Dentists are commonly the first to diagnose GERD through erosion of teeth since most people are not aware of the presence of the disease, as it was reported that there is a correlation between dental erosion and GERD patients where patients with GERD are found to have dental erosion and patients with dental erosion are then found to have GERD ${ }^{(6)}$.

The high acidity of the gastric components reaching the oral cavity is likely to cause more dental erosion compared with carbonated drinks ${ }^{(7)}$. Unlike dental caries, in which the demineralization is caused by an acidic environment produced by plaque bacteria, the acidic environment in GERD is due to the reflux of hydrochloric acid from the stomach. The erosive effect tends to be localized on the palatal aspects of the maxillary teeth; however, it can also extend to the occlusal and other surfaces of the dentition ${ }^{(8,9)}$.

Oral symptoms associated with GERD are burning mouth syndrome, dental sensitivity, loss of vertical occlusal dimension, and esthetic problems ${ }^{(10)}$. If tooth structure loss reaches such level of high severity, functional and esthetic rehabilitation of the teeth becomes necessary ${ }^{(11)}$. Therefore, the choice of an adequate restorative material plays an extremely relevant role in the durability of the restoration.

Ceramics have been the backbone of esthetic dentistry for more than 100 years. The qualitative improvements provided ceramic materials with many advantages over the porcelain-fused-tometal (PFM) system. Glass-ceramics have superior optical properties ${ }^{(12)}$. Stabilized zirconia, referred to as "ceramic steel", shows not only the unique phenomenon called "transformation toughness", but also other properties such as the highest strength amongst dental ceramics, high fracture toughness and Vickers hardness ${ }^{(9)}$. Meanwhile, the so-called "hybrid ceramics" appeared to have advantages in terms of fracture resistance, high resilience, and shock-absorbing properties, milling efficiency, polishability and accuracy due to less marginal chipping ${ }^{(13)}$. Ceramic materials with a resin matrix inside, are especially suitable to produce crowns over the implants or tooth restorations in a region where high masticatory pressure is generated ${ }^{(14)}$.

Although dental ceramics can provide the most natural replacements for teeth and are considered chemically inert restorative materials, many factors such as the composition, microstructure, chemical properties of ceramic materials, exposure to erosive or acidic agents, exposure time, and temperature, may influence the durability of dental ceramics ${ }^{(15)}$.

Surface features play a key role in the clinical longevity of restorative materials since superficial biodegradation resulting from chemical solutions will affect the material properties. This process will allow plaque accumulation, wear, and discoloration of restorations ${ }^{(16,17)}$.

Rough surfaces may also lead to abrasion of adjacent and opposing teeth and subsequently teeth staining. Therefore, the surface roughness of restorative materials should be minimized to contribute to the patient's comfort, optimum esthetics, oral hygiene, and satisfactory clinical performance ${ }^{(18)}$.

Sulaiman et al. ${ }^{(19)}$ studied the impact of gastric acid ( $\mathrm{pH}$ 1.2) on the surface topography of different monolithic zirconia and IPS e.max and found that IPS e.max and FSZ (fully stabilized zirconia) exhibited smoother surfaces after acid immersion. While Kulkarni et al. ${ }^{(5)}$ found that zirconia showed resistance to gastric acid and tooth brushing, whereas the gastric acid treatment affected the surface roughness of feldspathic porcelain and IPS e.max ceramics.

Dental ceramics present excellent physical and mechanical properties, such as biocompatibility with oral tissues, provided that the material is placed in an optimal environment. However, an aqueous environment and exposure to chemical solutions may create micro-cracks, resulting in increased surface roughness ${ }^{(20)}$. Therefore, the study was designed to evaluate the effect of simulated gastric acid on the surface roughness of different monolithic ceramic materials. 


\section{MATERIALS AND METHODS}

The materials used in this study are: group Z; Ceramil Zolid fx white (Amann Girrbach, Koblach, Austria), group E; IPS e.max CAD HT A3 (Ivoclar Vivadent AG, Schaan, Liechtenstein), group S; Vita Suprinity HT A3 (Vita Zanfabrik, Germany), and group C; Cerasmart HT A3 (GC, Tokyo, Japan). A total of 40 disks shaped from four ceramic materials (10 each) with $1.0 \mathrm{~mm}$ thickness were cut from the ceramic blocks for each material, except for zirconia, the disks were cut $20 \%$ larger to compensate for shrinkage after sintering.

Cuts were done using a low-speed diamond saw (Isomet saw 4000, Buehler, Illinois Tool Works Inc, USA) running under water coolant with a $2500 \mathrm{rpm}$ speed. A digital caliper (Fisher Scientific Traceable Caliper, USA) was used to confirm the thickness of the specimens after sawing.

The white zirconia disks were then colored, before sintering using Ceramill FX coloring liquid shade A3 ( Amann Girrbach, Koblach, Austria) for cubical zirconia according to manufacturer's instruction. A dipping technique was used; in which the disks were immersed into the coloring liquid for 10 seconds to absorb the color, then removed by a pair of plastic tweezers.

After coloring and before sintering, zirconia disks were pre-dried first at a temperature of $80^{\circ} \mathrm{C}$ for 60 minutes. Then, specimens were sintered at a temperature of $1450{ }^{\circ} \mathrm{C}$ in the high-temperature furnace (Ceramill Therm, Amann Girrbach AG, Herrschaftswiesen 16842 koblach, Austria) according to the manufacturer's instructions.

Ceramic disks of IPS e.max CAD and Vita Suprinity were crystallized in the furnace (Programat P310, Ivoclar Vivadent AG, Bendererstrasse 2, FL-9494 Schaan, Liechtenstein) with the specific program for each material according to manufacturer's instructions. Disks of the Cerasmart material don't need any further heat treatment, accordingly,, just polishing and cleaning were done.
Polishing of the specimens was done on one surface using Robinson's brush and polishing paste (Pearl Surface Z). After polishing, all specimens were cleaned using an ultrasonic cleaner (Silfradent, Santa Sofia, Forli-Cesena, Italy) in a distilled water bath for 10 minutes then left to air-drying over an absorbent paper.

After ultrasonic cleaning all ceramic disk specimens were weighed before and after gastric acid immersion by a micro-scale (AXIS Sp. z o.o. ul. Kartuska 375B, 80-125 Gdańsk, pomorskie, Poland).

A generic formula simulating gastric acid was used. Hydrochloric acid $(\mathrm{HCl})$ of $0.06 \mathrm{M}(\mathrm{pH} 1.2)$ was prepared according to previous studies ${ }^{(19,21)}$. The $\mathrm{pH}$ was monitored with $\mathrm{pH}$-meter (JENCO, Model No. 6173pH, SN. JC05788, made in China for JENCO USA) and the solution changed every $24 \mathrm{~h}$. Each ceramic disk was immersed individually with a polished surface facing up in $5 \mathrm{ml}$ of the simulated gastric acid for $96 \mathrm{~h}$ at $37^{\circ} \mathrm{C}$ in an incubator (Memmert, GmbH Co. KG, Schwabach, Germany).

Before and after immersion in the acid; the surface roughness $(\mathrm{Ra})$ was measured using a stylus profilometer (Surftest SJ 210, Mitutoyo Corp, Japan) which scans surface roughness with $5 \mu$ m-diameter diamond stylus and $90^{\circ}$ tip angle. To measure the roughness profile $(\mathrm{Ra})$ value in micrometers $(\mu \mathrm{m})$, the tracing diamond stylus (with $5 \mu \mathrm{m}$ tip radius) was moved across the surface (backward and forward) under a constant load of $4 \mathrm{mN}$ (measuring force) with a speed of $0.5 \mathrm{~mm} / \mathrm{sec}$ and a cut-off value of $0.8 \mathrm{~mm}$.

Calibration was checked with a standard ( $\mathrm{Ra}$ $=2.94 \mu \mathrm{m}$ ) before the first use and after every 10 samples. Three traces were recorded for each ceramic disk which oriented consistently and measured at 3 different parallel locations to determine $3 \mathrm{Ra}$ for each disk. Then the mean surface roughness measurement was calculated for each ceramic disk (average value) to be used later in the statistical analysis. 
All raw data were collected and tabulated, then represented in mean and standard deviation. Statistical analysis was performed using a computer software (SPSS V 20.0, SPSS Inc., IBM Corporation, NY, USA) for windows. Data were analyzed using One-way ANOVA followed by the Tukey post hoc test with $\mathrm{P} \leq 0.05$ significance level.

\section{RESULTS}

One-way ANOVA was conducted between groups to compare the effect of gastric acid immersion on surface roughness for the four types of ceramics \{zirconia (Z), IPS e.max CAD (E), vita Suprinity (S) and Cerasmart (C)\}. A Tukey post hoc test was used to show significance between pairs of groups. The significance level was set at $\mathrm{P} \leq 0.05$ with $95 \%$ Confidence Interval for the mean values.

\section{Surface Roughness (Ra) measurement:}

There was no statistically significant difference $(\mathrm{P}>0.05)$ for $\mathrm{Z}$ and $\mathrm{E}$ groups after acid immersion, while for $\mathrm{S}$ and $\mathrm{C}$ groups, there was a statistically significant difference $(\mathrm{P}<0.05)$ after acid immersion. Table (1), Figure (1).

TABLE (1): Ra comparison between before and after acid immersion among different materials:

\begin{tabular}{|c|c|c|c|c|c|c|}
\hline \multirow[b]{2}{*}{ Group } & \multicolumn{3}{|c|}{ Ra Before } & \multicolumn{3}{|c|}{ Ra After } \\
\hline & $\begin{array}{c}\text { Mean } \\
(\mu \mathrm{m})\end{array}$ & SD & P-value & $\begin{array}{c}\text { Mean } \\
(\mu \mathrm{m})\end{array}$ & SD & P-value \\
\hline Z & $0.256^{\mathrm{a}}$ & 0.05 & \multirow{4}{*}{$0.00^{*}$} & $0.236^{\mathrm{a}}$ & 0.02 & \multirow{4}{*}{$0.00^{*}$} \\
\hline E & $0.475^{\mathrm{b}}$ & 0.07 & & $0.414^{\mathrm{b}}$ & 0.07 & \\
\hline S & $0.474^{\text {bc }}$ & 0.06 & & $0.555^{\mathrm{e}}$ & 0.09 & \\
\hline $\mathrm{C}$ & $0.149^{d}$ & 0.01 & & $0.165^{f}$ & 0.01 & \\
\hline
\end{tabular}

Same letters mean non-significant, different letters mean significant, $(*)$ Significant $P \leq 0.05$

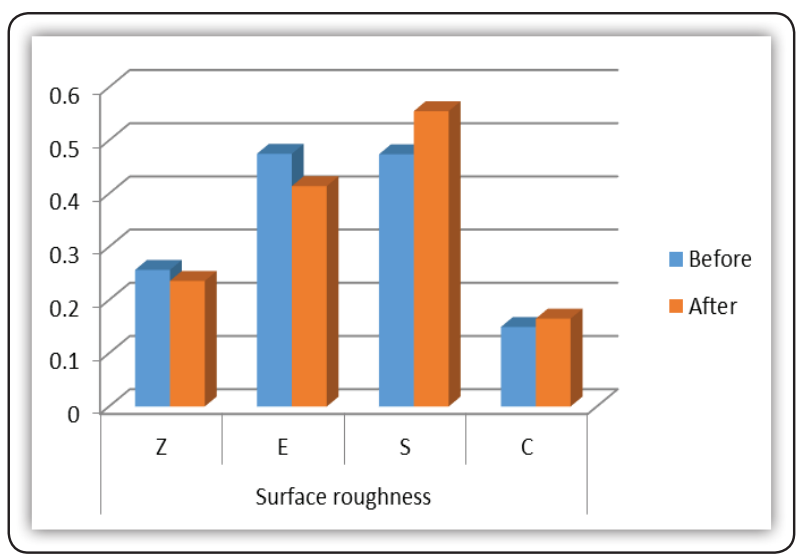

FIG (1) Bar chart showing surface roughness comparison among different materials before and after acid immersion.

- For group Z; surface roughness decreased after acid immersion but not statistically significant.

- For group E; surface roughness decreased after acid immersion but not statistically significant.

- For group $\mathrm{S}$; surface roughness increased significantly after acid immersion.

- For group C; surface roughness increased significantly after acid immersion.

\section{DISCUSSION}

The ultimate objective of restorative dentistry is to replace lost tooth structure with a material whose physical properties and mechanical performance are similar to that of natural teeth. All dental restorations are exposed to complex and varying oral conditions during their service life.

Dental professionals usually review medical histories and medications that identify patients with a diagnosis of acid reflux. Most often, a specialized physician known as a gastroenterologist treats this condition. However, there are dental manifestations to GERD, so it is important that dental professionals identify these patients and recommend appropriate dental treatment to maintain a long-term health of the dentition. Furthermore, dental professionals could recognize this condition in untreated patients and may need to refer those patients to a physician for further evaluation. 
If a GERD patient, or any similar condition, needs dental restorative treatment, the clinician must consider the effect of acid on the intended restorative material that will be used. Consequently, the choice of an adequate restorative material plays an extremely relevant role in the durability of the restoration. Therefore, this study was conducted to clarify this issue in term of surface roughness.

The ceramic materials used in this study were selected according to the availability in the market and the popularity of their use to represent their families. The ceramic materials were just polished then tested without glazing to determine the effect of gastric acid on the ceramic material itself, as the glaze layer is removed or peeled off after about six months ${ }^{(22)}$. Furthermore, several studies have shown that polishing methods can result in a final ceramic surface with a similar or better roughness than glaze-fired ceramic surfaces ${ }^{(18,23)}$.

Regarding the corrosive acid concentration and immersion time, there is no clear agreement in the literature of the actual method of acid simulation and the equivalent time to replicate an in-vivo model ${ }^{(19)}$. The ISO standard 6872 solubility test for dental ceramics advocates the use of a $4 \%$ acetic acid and a standard exposure time of $16 \mathrm{~h}$ at $80{ }^{\circ} \mathrm{C}^{(24)}$. The in-vivo relevance of this time was determined to be equivalent to approximately 2 years clinical situation based on the study by De Rijk et al. ${ }^{(25)}$ who reported that immersion in artificial saliva at $22{ }^{\circ} \mathrm{C}$ for 22 years would have been required to produce the same degree of dissolution as exposure to $4 \%$ acetic acid at $80^{\circ} \mathrm{C}$ for $168 \mathrm{~h}$.

The in-vitro simulation of corrosive effects of acids on the surface roughness of dental ceramics mainly depends on the concentration of the acid, the time of immersion, and the temperature. In the present study, a stronger acid ( $\mathrm{HCl}, \mathrm{pH} 1.2)$ was used as an ageing solution based on previous studies ${ }^{(19,21)}$ rather than the ISO standard 6872 of $4 \%$ acetic acid to represent the clinical situation of patients who have acid reflux disorder. Also, the immersion time was increased to $96 \mathrm{~h}$ at $37^{\circ} \mathrm{C}$, which is supposed to simulate over 10 years of clinical exposure in-vivo ${ }^{(19)}$.

The risk of these acids lies in its chelating effect that can cause degradation, ionic dissolution and release of alkaline lithium and aluminum ions, which are less stable in the glassy phase than in the crystalline phases, and results in the dissolution of the ceramic silicate network, which can be toxic ${ }^{(26,27)}$.

Resistance to chemical degradation of dental materials is a principal requirement for intra-oral use and is a relevant concern in choosing ceramic materials for restorations. Dental prostheses must resist degradation over both intermittent and constant exposure to harsh conditions arising from temperature changes and acid-base shifts ${ }^{(26)}$. Polymerbased materials may be more sensitive to aging factors than monolithic ceramics due to the infiltrated polymer and a large number of polymer/particle interfaces ${ }^{(28)}$. However, information considering the degradation of the recently developed materials under variation in $\mathrm{pH}$ conditions is limited. Hence, this study was designed to investigate the effects of acidic environment and low $\mathrm{pH}$ on surface roughness of different ceramic materials.

Surface roughening, however minor it can be, may lead to increased wear to the opposing dentition and increased bacterial adherence through mechanical entrapment. So, it is worth to remind that a positive correlation between surface roughness and plaque accumulation has been previously reported ${ }^{(18,29)}$.

The present study showed evident interactions indicating that tested ceramics are not chemically inert but showing some signs of degradation in an acidic environment, which is in agreement with other previous studies ${ }^{(26,30,31)}$.

In the present study, the four ceramic materials used were submitted for surface roughness measurement by a profilometer before and after immersion in simulated gastric acid for 96 hours at $37^{\circ} \mathrm{C}$ incubator. The results showed a statistically 
significant difference $(\mathrm{P}<0.05)$ after acid immersion for $\mathrm{S}$ and $\mathrm{C}$ groups, while for $\mathrm{Z}$ and $\mathrm{E}$ groups, there was no statistically significant difference $(P>0.05)$.

Zolid fx (group Z) showed a statistically nonsignificant $(\mathrm{P}>0.05)$ decrease in surface roughness. This may be due to the fact that Zolid fx is a fully stabilized zirconia which was stabilized in the cubic form by an increasing the amount of Yttria over 9 wt $\%$ rendering this material to be more stable under different situations, such as acidic environment and low $\mathrm{pH}$ in the present study. This result is in agreement with other studies that suggest that a higher dopant concentration of more than $8 \mathrm{wt} \%$ of Yttria plays a significant role in the emergence of ultra-translucent fully stabilized zirconia, ${ }^{(32)}$ which has more aging resistance than partially stabilized zirconia $^{(33)}$.

IPS e.max CAD (group E) showed a statistically non-significant $(\mathrm{P}>0.05)$ decrease in surface roughness after acid immersion. The fact that IPS e.max has a different microstructure than zirconia probably explains its higher weight loss after acid immersion. This finding may indicate that glass-ceramics have increased vulnerability to a corrosive acid when compared with zirconia. This result is in disagreement with other studies that showed a rougher surface after acid immersion for IPS e.max, concluding that the crystalline phase $\left(\mathrm{Li}_{2} \mathrm{Si}_{2} \mathrm{O}_{5}\right)$ appear to dissolve at a slower rate than the glass matrix creating a rougher surface $(19,26,31)$. However, the crystalline phase $\left(\mathrm{Li}_{2} \mathrm{Si}_{2} \mathrm{O}_{5}\right)$ in IPS e.max represents about $70 \%$ which is far more than the glassy phase, so the exposed surface may have a little glassy matrix that when dissolved in acid didn't make a significant difference in the results of the present study.

The surface roughness of Vita Suprinity (group $\mathrm{S})$ increased significantly $(\mathrm{P}<0.05)$ after acid immersion. Vita Suprinity is a zirconia-reinforced lithium silicate ceramic that includes $8-12 \% \mathrm{ZrO}_{2}$ in its composition, the acid may interact differently with these different phases making a rougher surface. Zirconia phase is more resistant to acid exposure, which is supported by the results of group Z, while lithium silicate phase (15-21 wt\%) and glass matrix (55-65 wt\%) are more vulnerable to acid attack. The presence of a glassy matrix may lead to the dissolution of the glass network, considering that alkaline ions ( $\mathrm{Si}, \mathrm{Ca}$, and $\mathrm{Mg}$ ) are less stable when in a glassy matrix phase than in a crystalline phase ${ }^{(30,31)}$. This is in agreement with previous studies in which the surface roughness of polished Vita Suprinity specimens increased after acid exposure ${ }^{(34,35)}$.

Likewise, the surface roughness of Cerasmart (group $\mathrm{C}$ ) increased significantly $(\mathrm{P}<0.05)$ after acid immersion. Cerasmart is composed of a resin matrix with silica and barium glass nanoparticles. The acid may attack the resin phase much more aggressively than it does with the glass phase, with the chemical bonds at the glass/polymer interface being damaged by hydrolysis near the surface in contact with the acid, leading to this increase in surface roughness.

Indeed, the resin part has high susceptibility to acid-induced degradation, resulting in loss of cohesion at the interface. When subjected to stronger acid solutions, the ester groups of the polymer were hydrolyzed by acid and a chain split occurred. Those polymer chains were cleaved to form oligomers and finally to form monomers ${ }^{(16,28,36)}$.

Along with the results in hands, the surface roughness of a material is determined by the behavior of acid toward each component of the material as there are some components which are more resistant to acid than others. In other words, the acid acts evenly on single-phase materials, while acts unevenly on multiphase materials causing its surface to be rough.

The limitation of this study is the absence of additional aging factors, including thermocycling and mechanical loading which could have contributed to having a deeper understanding of 
the properties and corresponding degradation of ceramic restorations.

As most monolithic crowns are stained and glazed, it would be interesting to further evaluate the effect of an acidic environment on the stability of such stains and how the esthetic appearance of a restoration is affected. Also, the effect of an acidic environment on the flexural strength of ceramic materials should be further investigated.

\section{CONCLUSION}

Within the limitations of this in-vitro study, it can be concluded that; Surface roughness increased significantly for Vita Suprinity and Cerasmart after gastric acid immersion, while decreased for Zolid fx and IPS e.max CAD but not significantly.

\section{REFERENCES}

1. Sapp JP, Eversole LR, Wysocki GP. Contemporary oral and maxillofacial pathology. 2nd ed. St. Louis: Mosby; 2004.

2. Lussi A, Jäggi T. Erosion-diagnosis and risk factors. Clin oral invest 2008 Mar; 12(1):5-13.

3. Moazzez R, Bartlett D. Intrinsic causes of erosion. In: Lussi A, Ganss C, editors. Erosive tooth wear: from diagnosis to therapy. Basel: Karger medical and scientific publishers; 2014; 360-442.

4. Dundar A, Sengun A. Dental approach to erosive tooth wear in gastroesophageal reflux disease. Afr Health Sci. 2014 Jun;14(2):481-6.

5. Kulkarni A, Rothrock J, Thompson J. Impact of Gastric Acid Induced Surface Changes on Mechanical Behavior and Optical Characteristics of Dental Ceramics. J Prosthodont. 2020 Mar; 29(3):207-18.

6. Pace F, Pallotta S, Tonini M, Vakil N, Bianchi Porro G. Systematic review: gastro-oesophageal reflux disease and dental lesions. Aliment Pharmacother 2008 Jun; 27(12):1179-86.

7. Bartlett DW, Coward PY. Comparison of the erosive potential of gastric juice and a carbonated drink in vitro. $\mathrm{J}$ Oral Rehabil. 2001 Nov; 28(11):1045-7.

8. Moazzez R, Anggiansah A, Bartlett DW. The association of acidic reflux above the upper oesophageal sphincter with palatal tooth wear. Caries Res. 2005 Nov-Dec; 39(6):475-8.
9. Turp V, Tuncelli B, Sen D, Goller G. Evaluation of hardness and fracture toughness, coupled with microstructural analysis, of zirconia ceramics stored in environments with different pH values. Dent Mater J. 2012 Nov; 31(6):891-902.

10. Ali DA, Brown RS, Rodriguez LO, Moody EL, Nasr MF: Dental erosion caused by silent gastroesophageal reflux disease. J Am Dent Assoc 2002 Jun; 133(6):734-7.

11. Soares LE, Lima LR, Vieira LD, Santo AM, Martin AA. Erosion effects on chemical composition and morphology of dental materials and root dentin. Microsc Res Tech 2012 Jun; 75(6):703-10.

12. Barizon KT, Bergeron C, Vargas MA, Qian F, Cobb DS, Gratton DG, Geraldeli S. Ceramic materials for porcelain veneers: part II. Effect of material, shade, and thickness on translucency. J Prosthet Dent. 2014; 112(4):864-70.

13. Facenda JC, Borba M, Corazza PH. A literature review on the new polymer infiltrated ceramic-network material (PICN). J Esthet Restor Dent. 2018 Jul; 30(4):281-6.

14. Silva LH, Lima E, Miranda RBP, Favero SS, Lohbauer U, Cesar PF. Dental ceramics: a review of new materials and processing methods. Braz Oral Res. 2017 Aug; 31(suppl):e58:133-46.

15. Milleding P, Haraldsson C, Karlsson S. Ion leaching from dental ceramics during static in vitro corrosion testing. $\mathrm{J}$ Biomed Mater Res 2002 Sep; 61(4):541-50.

16. Ferracane JL. Hygroscopic and hydrolytic effects in dental polymer networks. Dent Mater 2006 Mar; 22(3):211-22.

17. Padovani GC, Fúcio SB, Ambrosano GM, Sinhoreti MA, Puppin-Rontani RM. In situ surface biodegradation of restorative materials. Oper Dent 2014 Jul; 39(4):349-60.

18. Jagger DC \& Harrison A. An in vitro investigation into the wear effects of unglazed, glazed and polished porcelain on human enamel. J Prosthet Dent. 1994 Sep; 72(3):320-3.

19. Sulaiman TA, Abdulmajeed AA, Shahramian K, Hupa L, Donovan TE, Vallittu P, Närhi TO. Impact of gastric acidic challenge on surface topography and optical properties of monolithic zirconia. Dent Mater. 2015 Dec; 31(12):1445-52.

20. Ccahuana VZ, Özcan M, Mesquita AM, Nishioka RS, Kimpara ET, Bottino MA. Surface degradation of glass ceramics after exposure to acidulated phosphate fluoride. $\mathrm{J}$ Appl Oral Sci 2010 Apr; 18(2):155-65.

21. Hunt D, McIntyre J. The development of an in vitro model of dental erosion. J Dent Res 1992;71:985.

22. Sulaiman TA, Camino RN, Cook R, Delgado AJ, Roulet J-F, Clark WA. Time-lasting ceramic stains and glaze: A toothbrush simulation study. J Esthet Restor Dent. 2020 Apr; 1-5. 
23. Sarikaya I, Güler AU. Effects of different polishing techniques on the surface roughness of dental porcelains. J Appl Oral Sci 2010 Feb; 18(1):10-6.

24. International Standards for Dental Ceramics. ISO 6872. Geneva, Switzerland: International Organization for Standardization; 1995. In Sulaiman TA, Abdulmajeed AA, Shahramian K, Hupa L, Donovan TE, Vallittu P, Närhi TO. Impact of gastric acidic challenge on surface topography and optical properties of monolithic zirconia. Dent Mater. 2015 Dec;31(12):1445-52.

25. De Rijk WG, Jennings KA, Menis DL. A comparison of chemical durability test solutions for dental porcelains. In: Sauer BW, editor. Biomedical engineering - recent developments. Proceedings of Biomedical Engineering Conference. New York: Pergamon Press, 1985 Jan; p. 152-5.

26. Anusavice KJ. Degradability of dental ceramics. Adv Dent Res 1992 Sep; 6(1):82-9.

27. Kukiattrakoon B, Hengtrakool C, Kedjarune-Leggat U, Effect of Acidic Agents on Surface Roughness of Dental Ceramics. Dent Res J 2011; 8(1):6-15.

28. Prakki A, Cilli R, Mondelli RF, Kalachandra S, Pereira JC. Influence of $\mathrm{pH}$ environment on polymer based dental material properties. J Dent 2005 Feb; 33(2):91-8.

29. Kawai K \& Urano M. Adherence of plaque components to different restorative materials. Oper Dent $2001 \mathrm{Jul}$; 26(4):396-400.

30. Kukiattrakoon B, Hengtrakool C, Kedjarune-Leggat U. Chemical durability and microhardness of dental ceramics immersed in acidic agents. Acta Odontol Scand 2010 Jan; 68(1):1-10.

31. Kukiattrakoon B, Junpoom P, Hengtrakool C. Vicker's microhardness and energy dispersive $\mathrm{x}$-ray analysis of fluorapatite-leucite and fluorapatite ceramics cyclically immersed in acidic agents. J Oral Sci 2009; 51(3):443-50.

32. Elsaka SE. Optical and mechanical properties of newly developed monolithic multilayer zirconia. J Prosthodont 2019 Jan; 28(1):e279-84.

33. Kontonasaki E, Giasimakopoulos P, Rigos AE. Strength and aging resistance of monolithic zirconia: an update to current knowledge. Jpn Dent Sci Rev. 2020 Dec; 56(1): $1-23$.

34. El Sokkary A, Elguindy J, El Shihi O. Effect of Surface Finish and Acidic pH Media on the Surface Roughness and the Color Stability of Zirconium Reinforced Lithium Silicate Glass Ceramics (An In-Vitro Study). Acta Scientific Dental Sciences 2018; 2(3):21-7.

35. Firouz F, Vafaee F, Khamverdi Z, Khazaei S, Ghorbani Gholiabad S, Mohajeri M. Effect of Three Commonly Consumed Beverages on Surface Roughness of Polished and Glazed Zirconia-Reinforced Lithium Silicate Glass Ceramics. Front Dent. 2019; 16(4):296-302.

36. Yu P, Xu Z, Arola DD, Min J, Zhao P, Gao S. Effect of acidic agents on the wear behavior of a polymer infiltrated ceramic network (PICN) material. J Mech Behav Biomed Mater 2017 Oct; 74:154-63. 